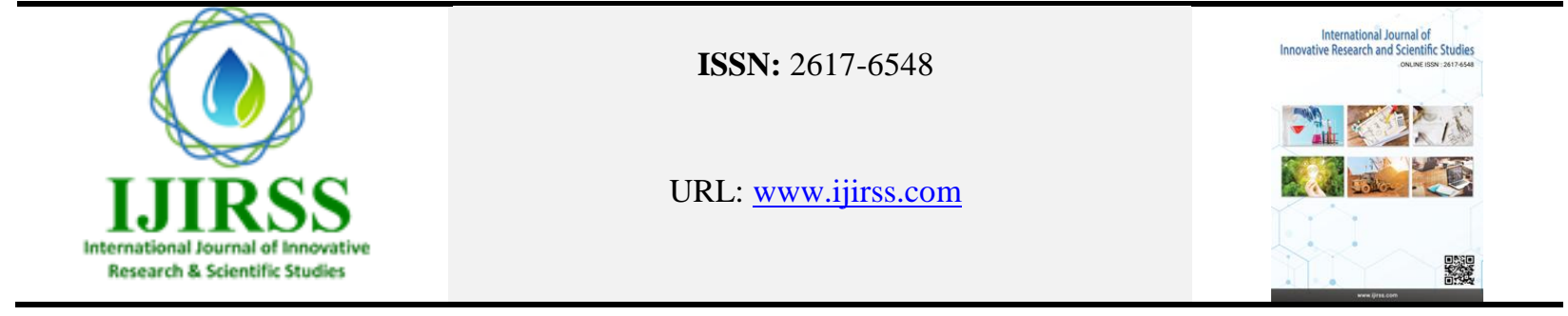

\title{
Finding Different Learning Methods of Chemistry Department Students, Education Faculty of Jawzjan University
}

\author{
Ghulam Nabi Adil ${ }^{1 *}$, Muhammad Hussain Neda ${ }^{2}$, Zaynab Dahi ${ }^{1}$ \\ ${ }^{1}$ Faculty of Education, Jawzjan University, Jawzjan, Afghanistan \\ ${ }^{2}$ Faculty of Natural Sciences, Shaheed Professor Rabbani Education University, Kabul, Afghanistan \\ *Corresponding author: Ghulam Nabi Adil (nabiaadil@yahoo.com)
}

\begin{abstract}
This research has been titled (Finding different learning methods of chemistry department students, education faculty of Jawzjan University). The overall aim of this study is to evaluate different styles of student's learning in chemistry department and to find the most common used methods of learning as well. The importance of this study is the novelty of the topic which has not been investigated so far. This paper also focuses on the challenges and problems that students face in different ways of learning in chemistry department of education faculty. Both quantitative and qualitative methods have been used in this research and the questionnaire has been used for the data collection. In expressing the issue about the importance of learning, learning from the perspective of scientists, problems and challenges in lack of learning, the consequences of lack of learning by students in higher education institutes, schools, family, the individual and the entire community are discussed. In the theoretical part of this research, theories of behaviorism (Thorndike's neural connection theory, contingent reflection theory, factor conditional theory), and cognitive theories (Gestalt theory, Bandura's social learning, Davit-ausubel's meaningful verbal discovery theory) has been used. In addition, in theoretical framework of this research, Thorndike's neural communication theories, Bandura's social learning, Bruner exploration learning, DavidAusubel's verbal meaningful learning have been applied. The results of this study revealed that most of the students in chemistry department of education faculty at Jawzjan University are not aware of learning methods, while only $14.02 \%$ of students are familiar with the methods of learning. To achieve accurate results the hypothesis (students' learning methods are supposed to vary widely) are very clearly analyzed.
\end{abstract}

Keywords: Learning theories, Learning styles, Learning factors, Learning challenges.

DOI: $10.53894 /$ ijirss.v2i1.13

Funding: This study received no specific financial support.

History: Received: 4 January 2019/Revised: 18 January 2019/Accepted: 16 February 2019/Published: 20 February 2019

Licensed: This work is licensed under a Creative Commons Attribution 4.0 License $(\mathrm{cc})$ EY

Acknowledgement: All authors contributed to the conception and design of the study.

Competing Interests: The authors declare that they have no conflict of interests.

Transparency: The authors confirm that the manuscript is an honest, accurate, and transparent account of the study was reported; that no vital features of the study have been omitted; and that any discrepancies from the study as planned have been explained.

Ethical: This study follows all ethical practices during writing. 


\title{
دريافت شيوه هاى مختلف يادكيرى محصلان ديبارتمنت كيمياى فاكولته تعليم و تربيه دانشخاه جوزجان
}

\author{
غلام نبى عادل1، "، محمد حسين ندا2، زينب داهى1

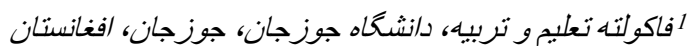

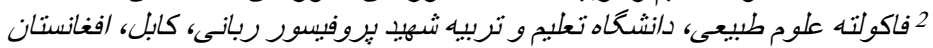

\begin{abstract}
خلاصه

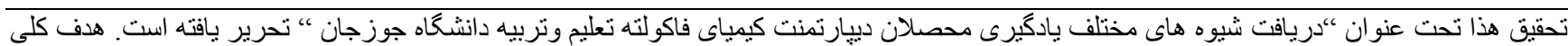

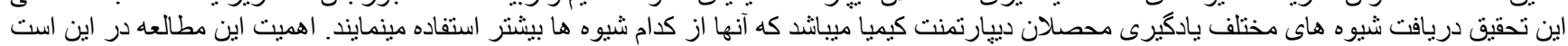

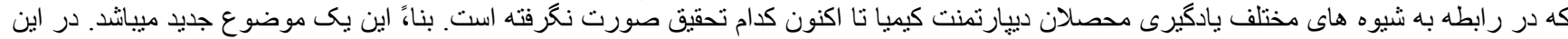

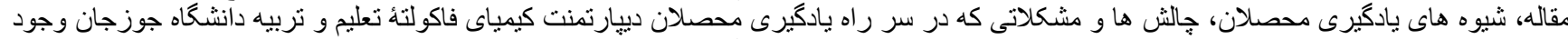

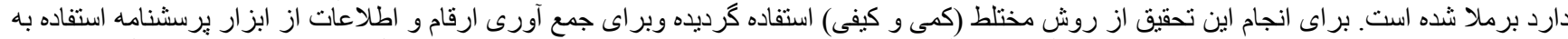

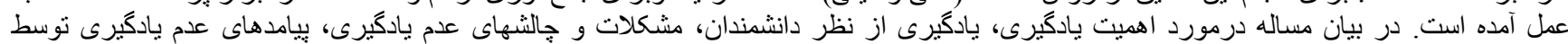

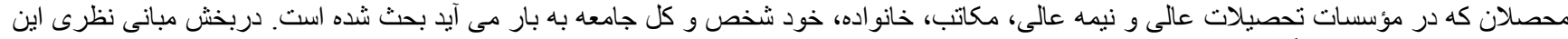

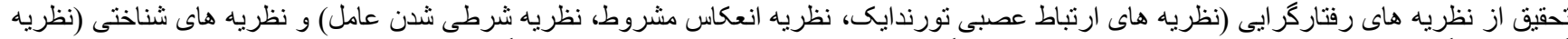

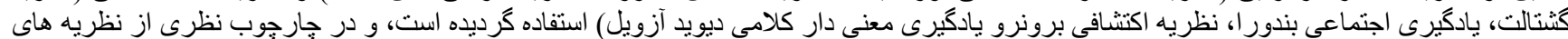

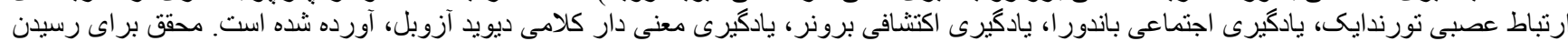

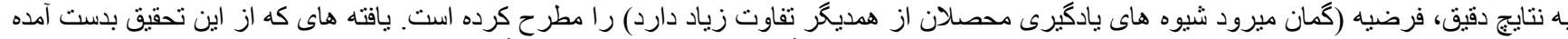

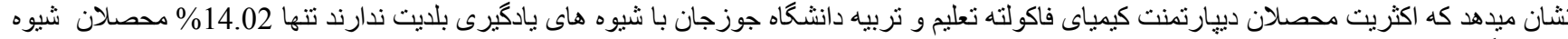
هاى يادكيرى ران إلد اندئ
\end{abstract}

كلمات كليلى: نظريه هاى يادكيرى، شيوه هاى بادكيرى، عو امل موثز بر يادكيرى، جالثهاى يادكيرى.

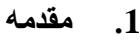

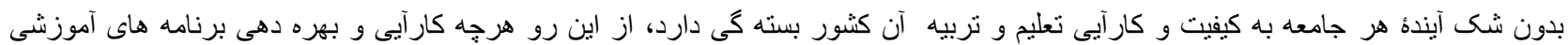

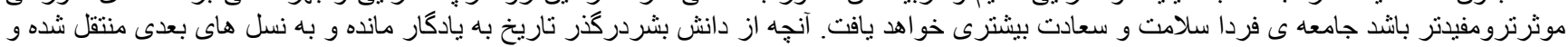

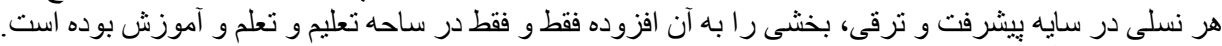

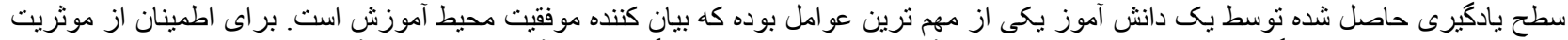

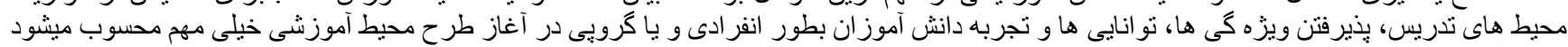

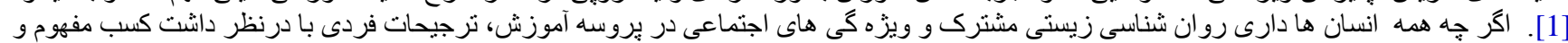

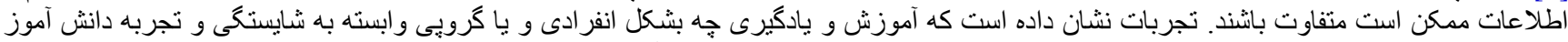

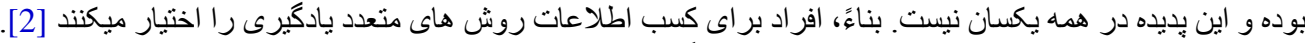

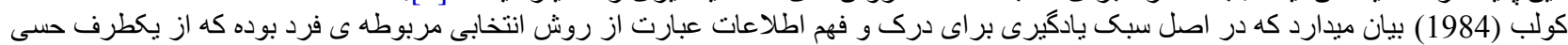

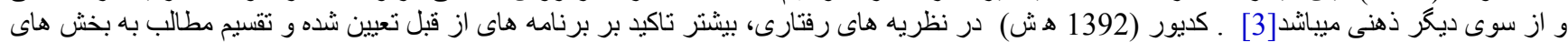

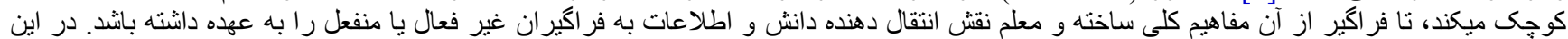

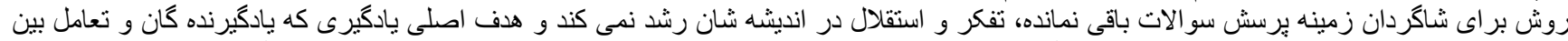

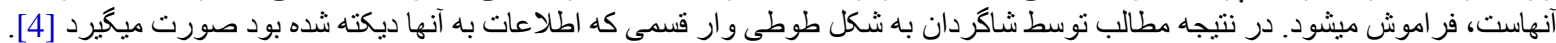

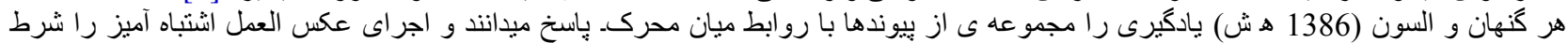

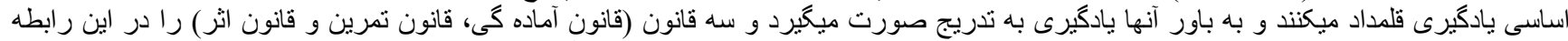

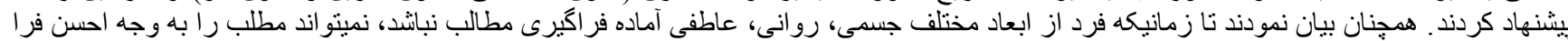

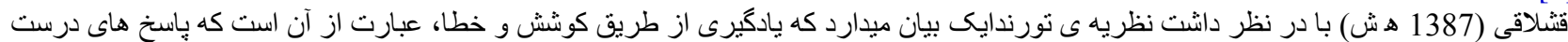

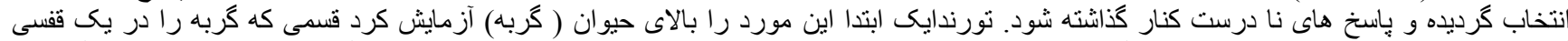

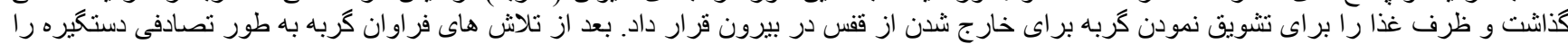

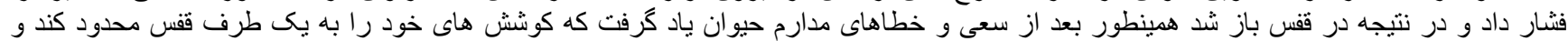

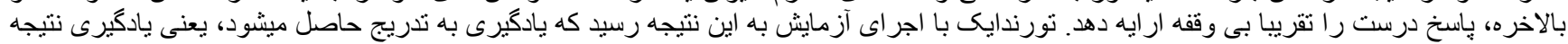

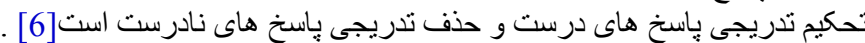

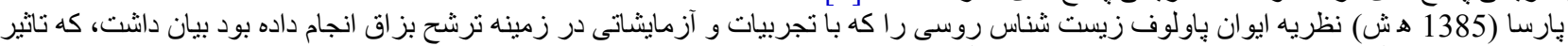

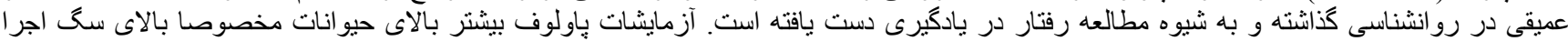

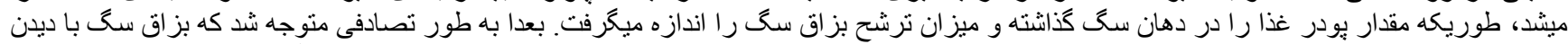

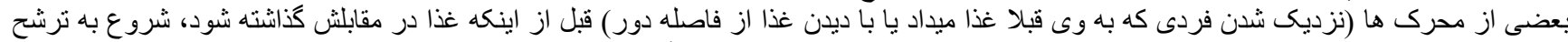

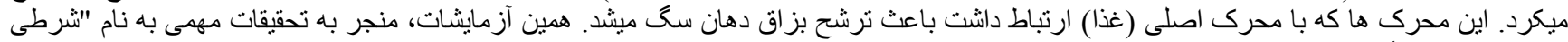

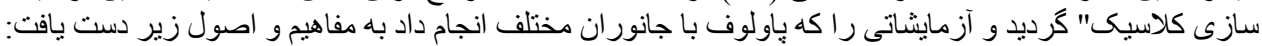

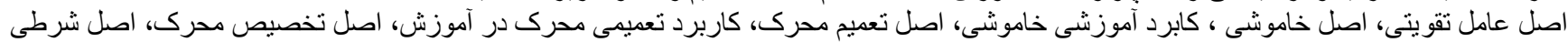

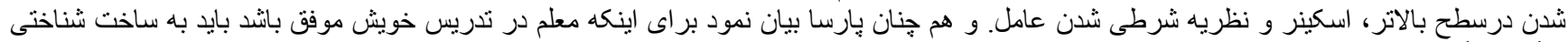

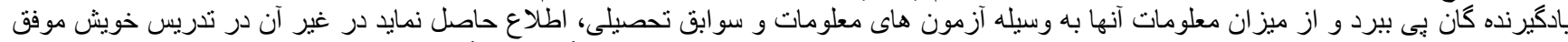

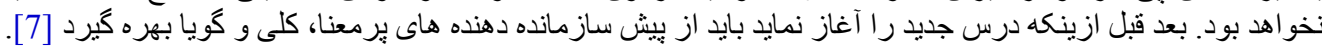

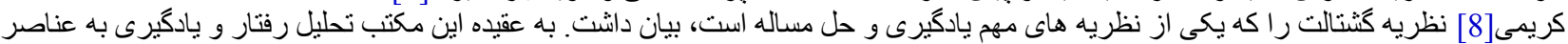

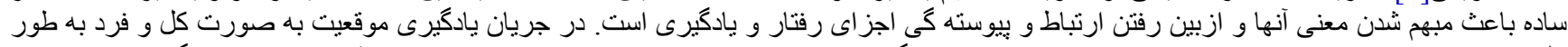

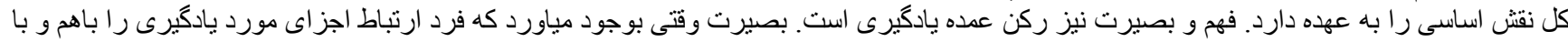




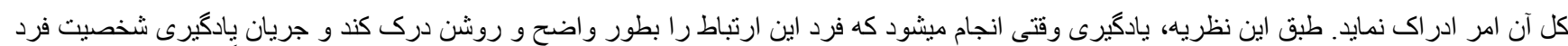

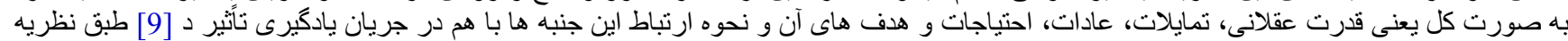

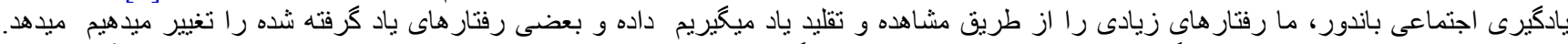

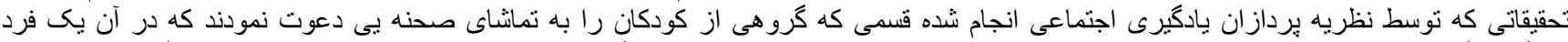

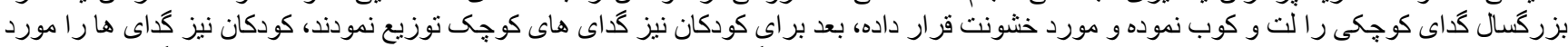

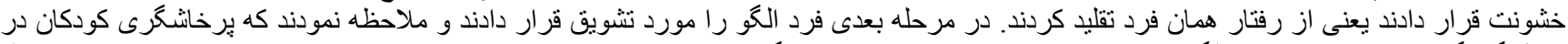

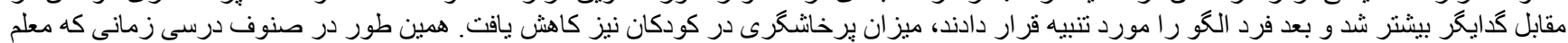

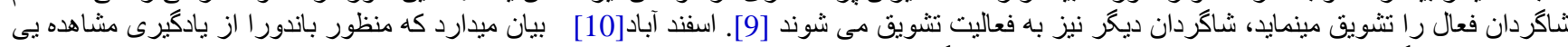

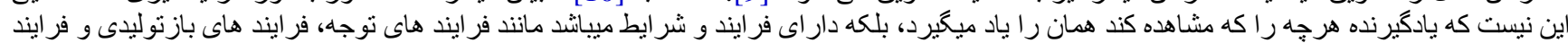

هايى انكيزشى [10].

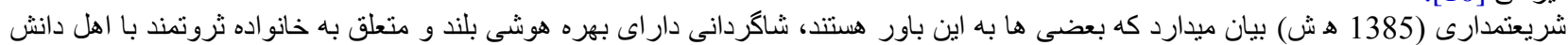

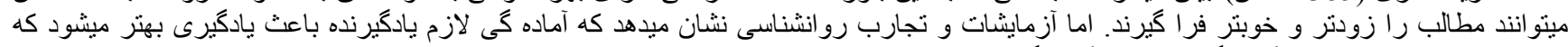

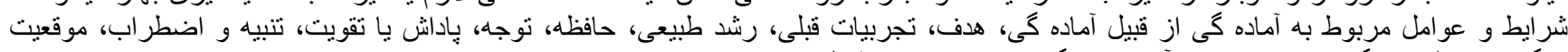

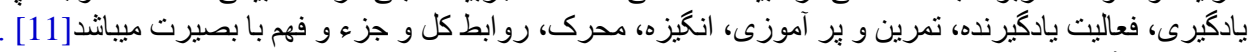

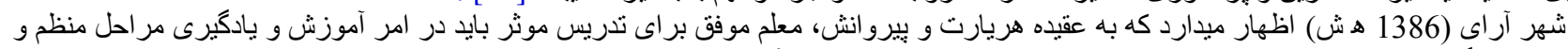

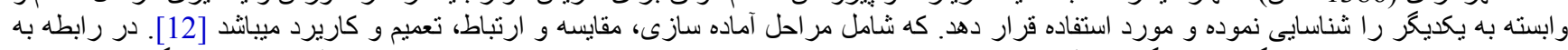

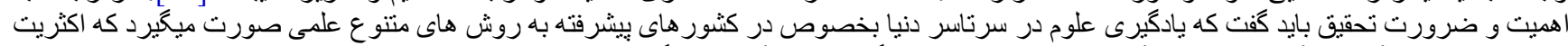

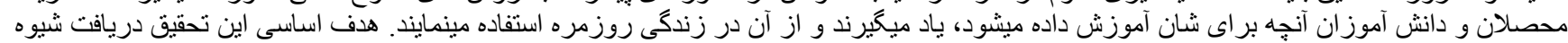

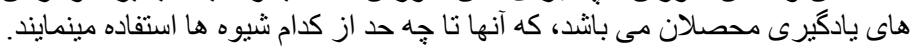

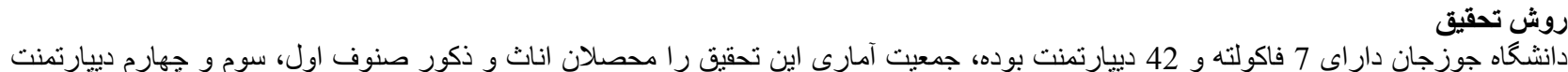

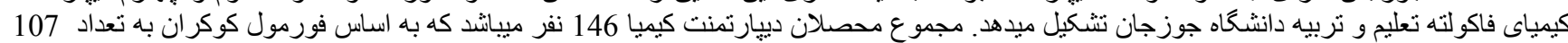

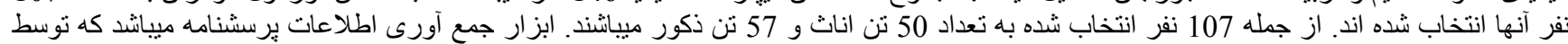

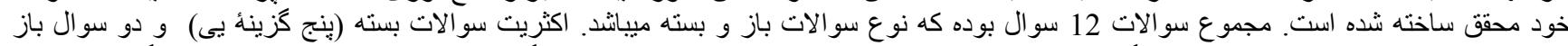

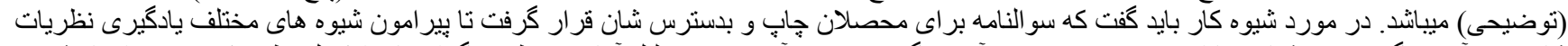

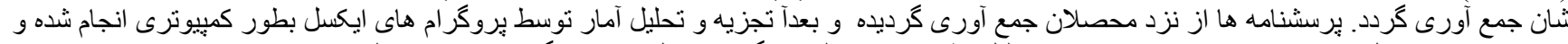

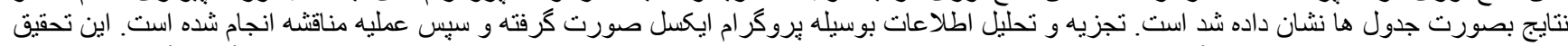

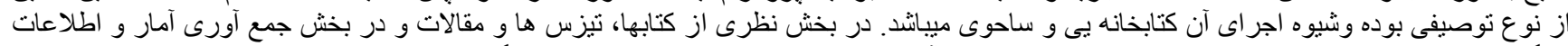

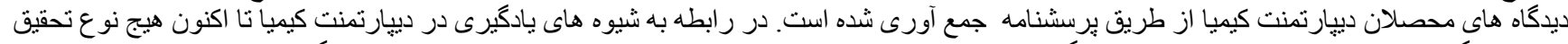

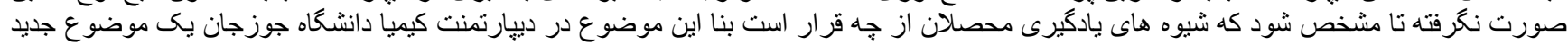

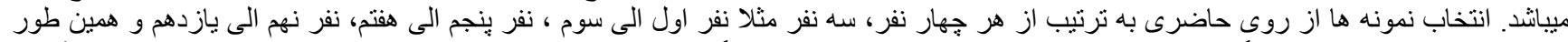

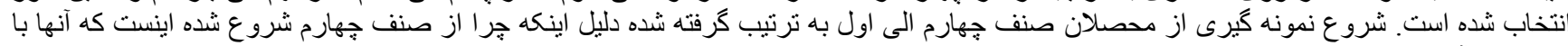

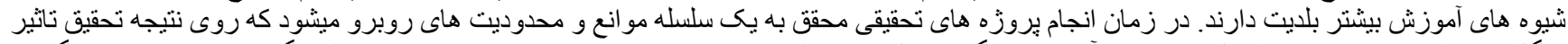

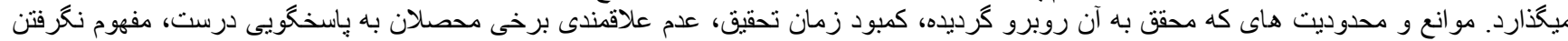

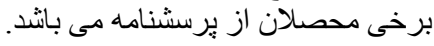

3.

3.1

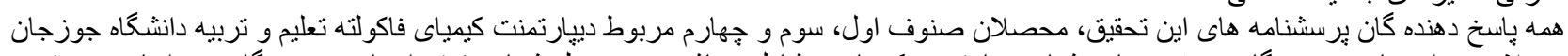

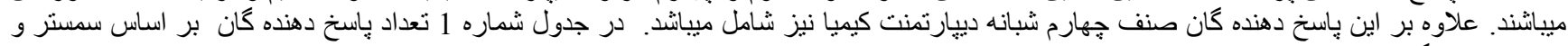
فيصدى ار ائه كرديده استا بر ائن.

\begin{tabular}{|c|c|c|}
\hline فيصدى & تعداد & سمستر ها \\
\hline 24.30 & 26 & دوم \\
\hline 29.90 & 32 & ينجم \\
\hline 29.90 & 32 & هفتم \\
\hline 15.89 & 17 & هفتم شبانه \\
\hline 100.00 & 107 & مجموع \\
\hline
\end{tabular}

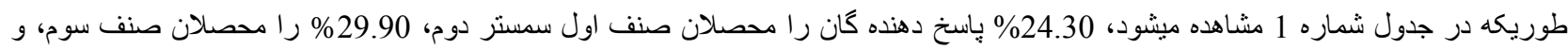

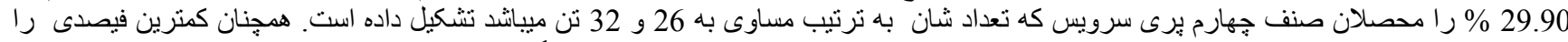

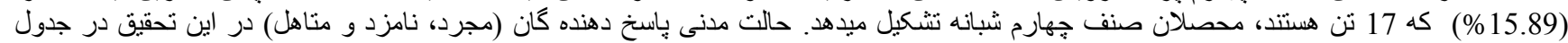
شماره 2 نشان داده شده است. 


\begin{tabular}{|c|c|c|}
\hline فيصدى & تعداد & كزينه ها \\
\hline 64.49 & 69 & مجرد \\
\hline 11.21 & 12 & نامزد \\
\hline 24.30 & 26 & متاهل \\
\hline 0 & 0 & بحى جواب \\
\hline 100.00 & 107 & مجموع \\
\hline
\end{tabular}

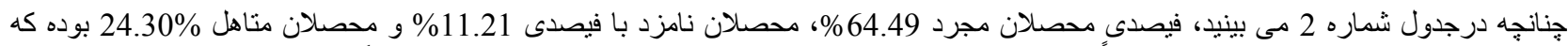

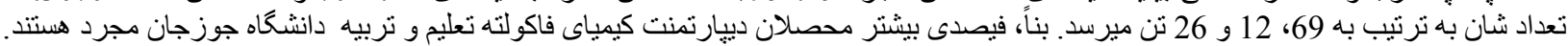

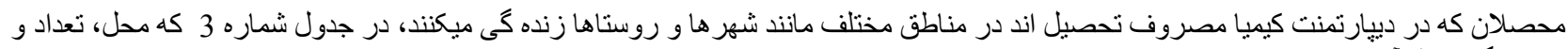
فيصدى زنده كى محل كهن در ديار را بيان ميكند، نشان داده شده است جدول 3: محل سكونت، تعداد و فيصدى محصلان

\begin{tabular}{|c|c|c|}
\hline فيصدى & تعداد & كزينه ها \\
\hline 44.86 & 48 & شهر \\
\hline 55.14 & 59 & روستا \\
\hline 0 & 0 & بى جواب \\
\hline 100 & 107 & مجموع \\
\hline
\end{tabular}

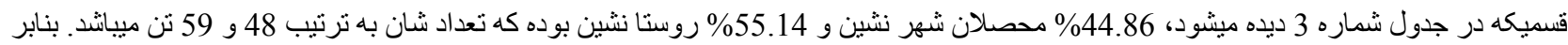

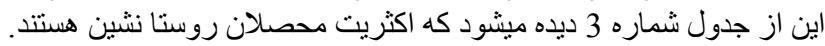

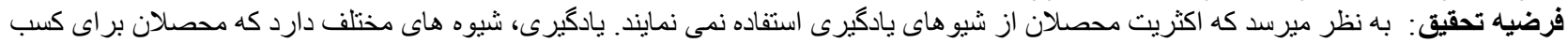

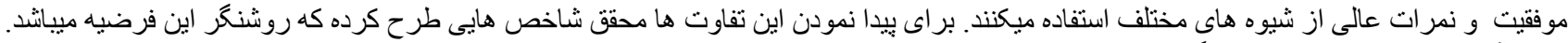
3.2

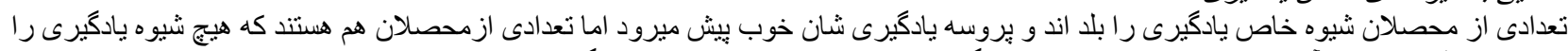

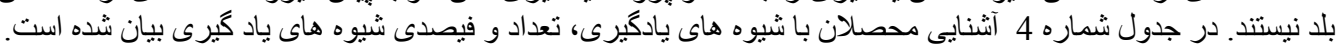

\begin{tabular}{|c|c|c|}
\hline فيصدى & تعداد & كزينه ها \\
\hline 82.24 & 88 & بلى \\
\hline 17.76 & 19 & نخير \\
\hline 0.00 & 0 & بى جواب \\
\hline 100.00 & 107 & مجموع \\
\hline
\end{tabular}

طوريكه در جدول شماره 4 مشاهده ميكردد، بيشترين فيصدى (82.24\%) را را محصلانى نشكيل ميدهند كه با شيوه هاى يادكيرى آثنايى دارند اما

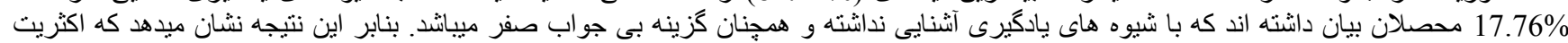

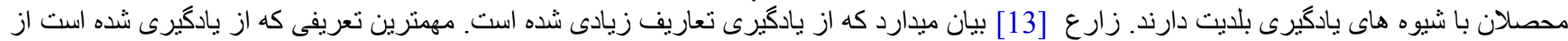

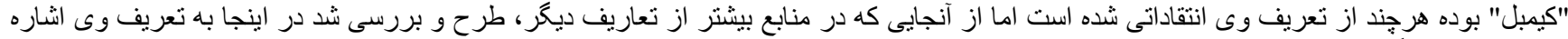

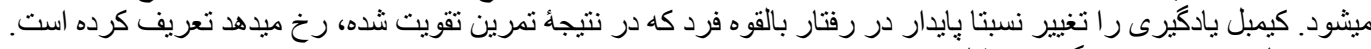
3.3

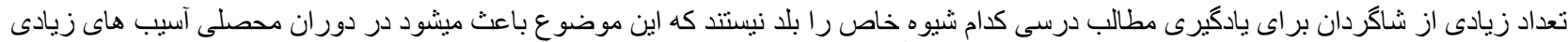

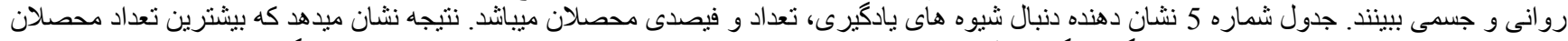

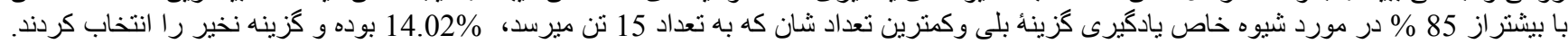

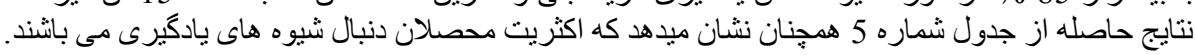

\begin{tabular}{|c|c|c|}
\hline فيصدى & تعداد & كزينه ها \\
\hline 85.98 & 92 & بلى \\
\hline 14.02 & 15 & نخير \\
\hline 0.00 & 0 & بي جواب \\
\hline 100.00 & 107 & مجموع \\
\hline
\end{tabular}


3.4

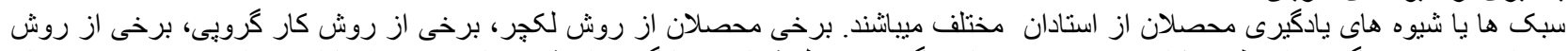

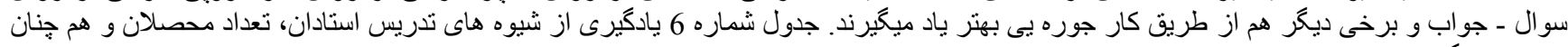

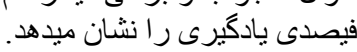

\begin{tabular}{|c|c|c|}
\hline فيصدى & تعداد & كزينه ها \\
\hline 25.23 & 27 & لكجز \\
\hline 29.91 & 32 & كار كرويى \\
\hline 41.12 & 44 & سوال و جواب \\
\hline 3.74 & 4 & كار جوره يیى \\
\hline 100.00 & 107 & مجموع \\
\hline
\end{tabular}

قسميكه در جدول شماره 6 ديده ميشود، 25.23\% كزينه لكجر،

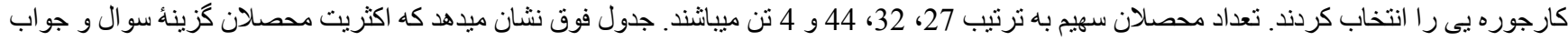
را انتخاب نموده اند. 3.5

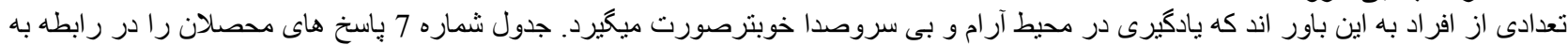

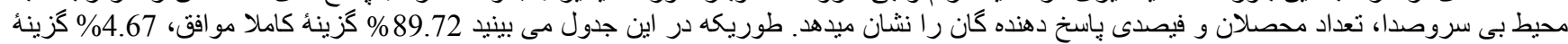

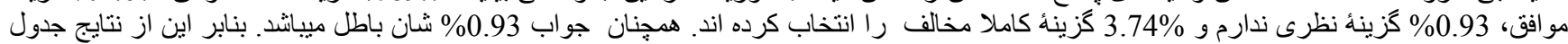

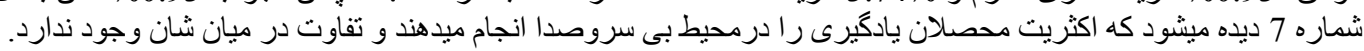

\begin{tabular}{|c|c|c|}
\hline فيصدى & تعداد & كزينه ها \\
\hline 89.72 & 96 & كاملا موافق \\
\hline 4.67 & 5 & موافق \\
\hline 0.93 & 1 & نظرى ندارم \\
\hline 0.00 & 0 & مخالف \\
\hline 3.74 & 4 & كاملا مخالف \\
\hline 0.93 & 1 & بى جواب \\
\hline 100.00 & 107 & مجموع \\
\hline
\end{tabular}

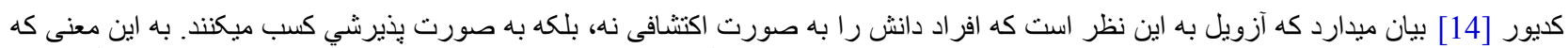

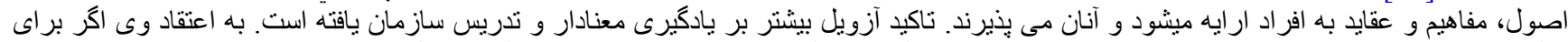

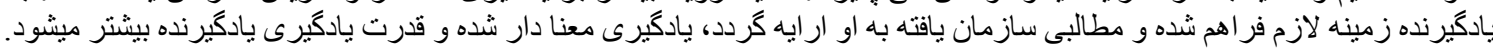

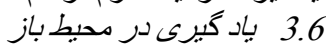

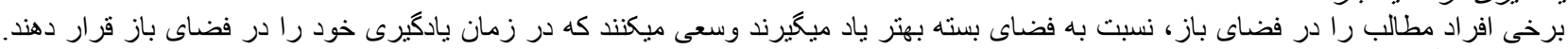

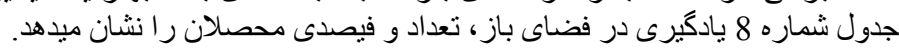
جدول 8: يادكيرى در محيط باز ، تعدادو فيصدى ياستخ دهنده كان

\begin{tabular}{|c|c|c|}
\hline فيصدى & تعداد & كزينه ها \\
\hline 54.21 & 58 & كاملا موافق \\
\hline 33.64 & 36 & موافق \\
\hline 3.74 & 4 & نظرى ندارم \\
\hline 2.80 & 3 & مخالف \\
\hline 3.74 & 4 & كاملا مخالف \\
\hline 1.87 & 2 & بع جواب \\
\hline 100.00 & 107 & مجموع \\
\hline
\end{tabular}

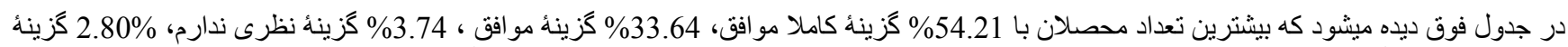

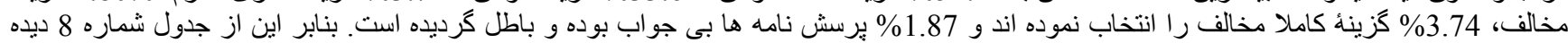


ميشو د كه اكثريت محصلان يادكيرى در محيط باز را بيشتر دوست دارند.

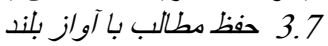

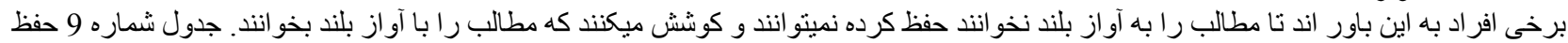
مطالب را به آواز بلند ، تعداد انتتر اك كننده كان و فيصدى محصلان را را بيان ميدارد.

\begin{tabular}{|c|c|c|}
\hline فيصدى & تعداد & كزينه ها \\
\hline 32.71 & 35 & كاملا موافق \\
\hline 23.36 & 25 & موافق \\
\hline 18.69 & 20 & نظرى ندارم \\
\hline 20.56 & 22 & مخالف \\
\hline 2.80 & 3 & كاملا مخالف \\
\hline 1.87 & 2 & بع جواب \\
\hline 100.00 & 107 & مجموع \\
\hline
\end{tabular}

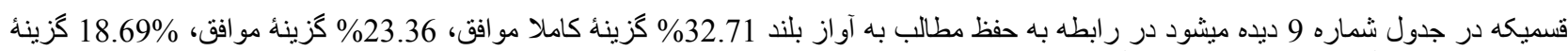

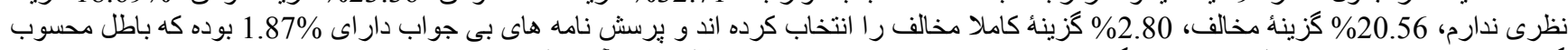

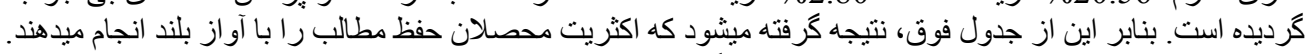

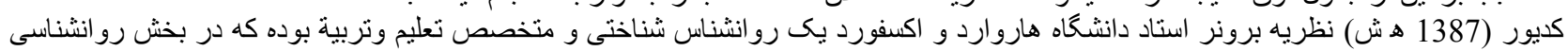

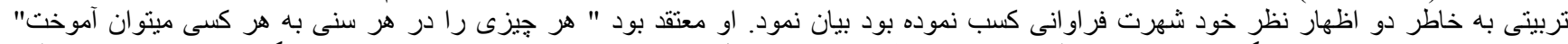

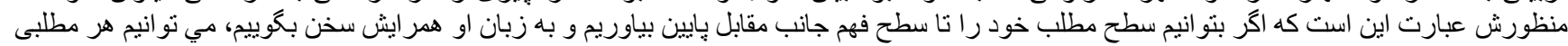

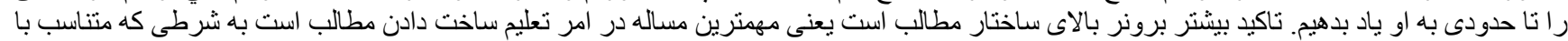

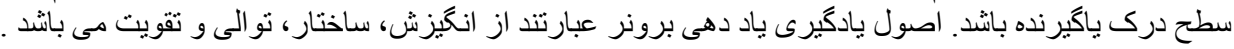
(3.8 3.8

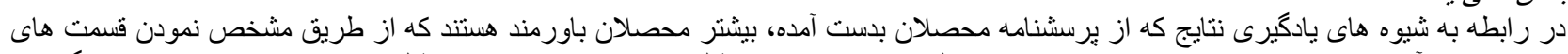

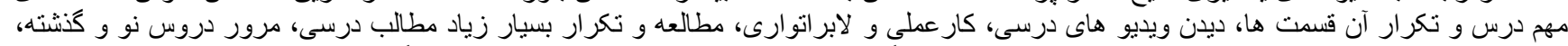

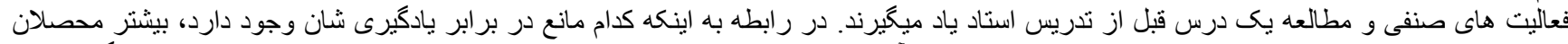

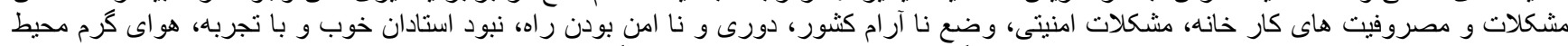

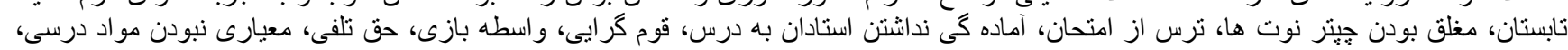

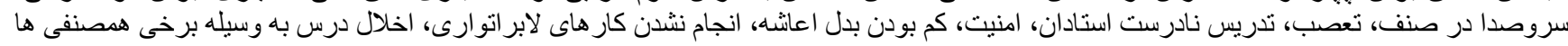
را بيان نموده اند.

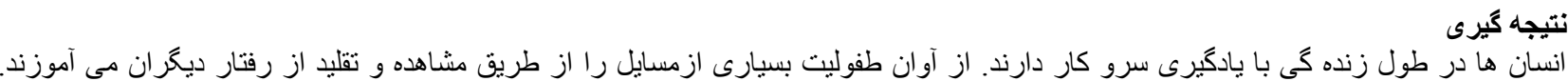

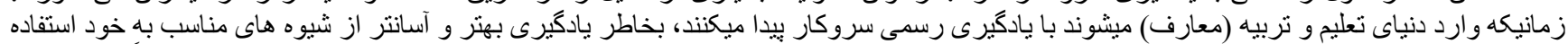

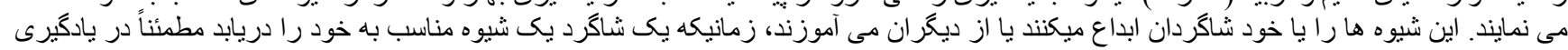

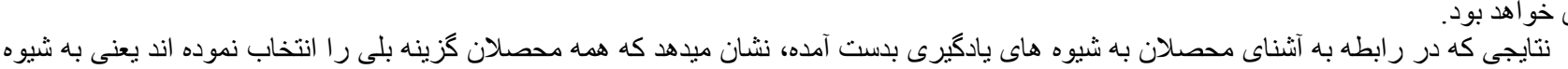

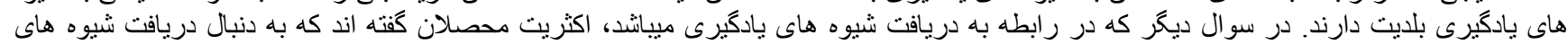

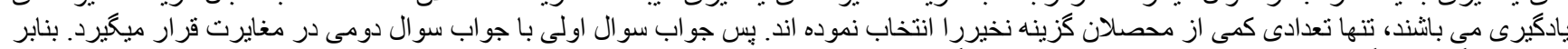

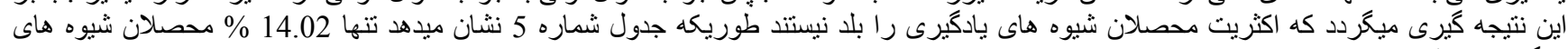

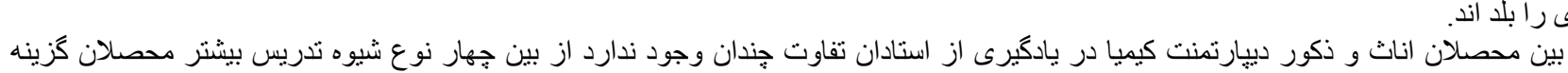
يادكيرى را بلد اند.

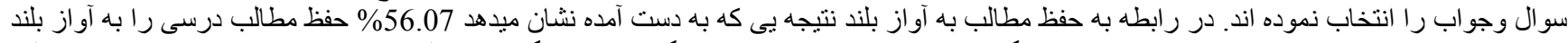

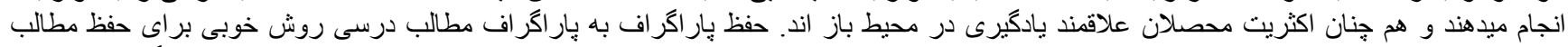

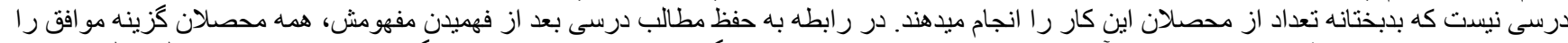

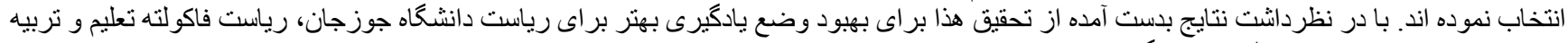

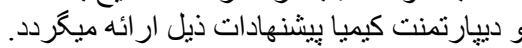

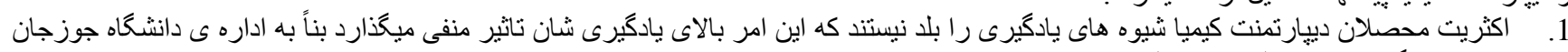

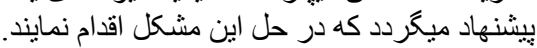

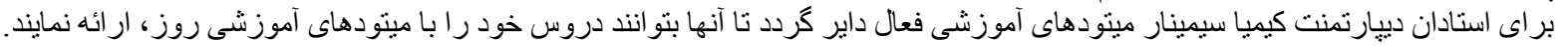

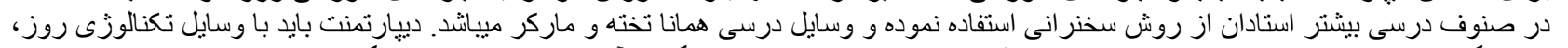

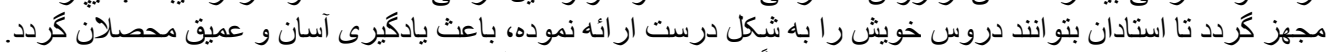

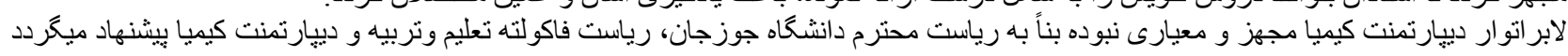




\section{References}

[1] J. E. Kemp, G. R. Morrison, and S. M. Ross, "Designing effective instruction," 1998.

[2] M. Yilmaz-Soylu and B. Akkoyunlu, "The effect of learning styles on achievement in different learning environments," Turkish Online Journal of Educational Technology-TOJET, vol. 8, pp. 43-50, 2009.

[3] D. A. Kolb, "Experiential learning : Experience as the source of learning and development," 1984.

[4] Educational Psychology, 12th ed. Tehran: Arasbaran, 1392.

[5] Child and Adolescent Learning Psychology, 4th ed. Tehran: Arian, 1386.

[6] Learning Psychology, 3th ed. Isfahan: Mani Publications, 1387.

[7] Educational Psychology, "Nineteenth edition," ed Tehran: Amirkabir Publishing Institute., 1385, p. 546.

[8] Karimi Educational Psychology, 12th ed. Tehran: Arasbaran, 1392.

[9] Teaching Methods and Techniques, 13th ed.: Contemporary Publications, 1382.

[10] Psychology of Individual Differences, 1st ed. Tehran: Samat Publications, 1389.

[11] Learning Psychology. Tehran: Payame Noor University, 1385.

[12] S. Every and M. Elson, An introduction to learning theories. Translated by Ali Akbar Seif, 11 ed. Tehran: Samat Publications, 1386.

[13] Learning Psychology, 12th ed.: Payame Noor University, 1391.

[14] Educational Psychology, 12th ed. Tehran: Samat Publications, 1387. 